\title{
A Narrative Review of Ultrathin-strut Drug-eluting Stents: The Thinner the Better?
}

\author{
Maik J Grundeken ${ }^{1}$ and Marcel AM Beijk ${ }^{1}$ \\ 1. Department of Cardiology, Amsterdam University Medical Centre - location AMC, Amsterdam, The Netherlands
}

DOI: https://doi.org/10.17925/HI.2021.15.2.84

\begin{abstract}
$\mathrm{S}$ econd-generation drug-eluting stents (DES) are considered standard of care for revascularization of patients undergoing percutaneous coronary intervention. Besides the polymer and antiproliferative drug used, the metallic backbone of DES is an attractive target for further development. Ultrathin-strut DES ( $\leq 70 \mu \mathrm{m}$ strut thickness) are more flexible, have an improved trackability and crossability compared to conventional second-generation DES. Importantly, ultrathin-strut DES reduce the risk of in-stent restenosis, thereby decreasing the risk of angiographic and clinical restenosis. In this narrative review, we will discuss the clinical outcomes of the commercially available ultrathin-strut DES.
\end{abstract}

\section{Keywords}

Coronary artery disease, drugeluting stents, percutaneous coronary intervention, stents, ultrathin struts, stent design, clinical outcomes, review

Disclosures: Maik J Grundeken and Marcel AM Beijk have no financial or non-financial relationships or activities to declare in relation to this article.

Review process: Double-blind peer review.

Compliance with ethics: This study involves a review of the literature and did not involve any studies with human or animal subjects performed by any of the authors.

Data availability: Data sharing is not applicable to this article as no datasets were generated or analyzed during the writing of this article.

Authorship: The named authors meet the International Committee of Medical Journal Editors (ICMJE) criteria

for authorship of this manuscript, take responsibility

for the integrity of the work as a whole, and have given final approval for the version to be published.

Access: This article is freely accessible at

touchCARDIO.com (C) Touch Medical Media 2021

Received: 12 September 2021

Accepted: 15 October 2021

Published online: 21 December 2021

Citation: Heart International. 2021;15(2):84-93

corresponding author: Marcel AM Beijk,

Amsterdam University Medical Center - location

AMC, Meibergdreef 9, 1105 AZ, Amsterdam, The

Netherlands. E: m.a.beijk@amsterdamumc.nl

Support: No funding was received for the publication of this article.
The first coronary stent was implanted by sigwart and Puel in $1986 .{ }^{1}$ Coronary stents were initially used to treat failure of balloon angioplasty treatment, i.e. as bail-out for acute vessel closure (due to dissections) or restenosis (due to elastic recoil). After the BENESTENT and STRESS landmark randomized trials, the routine use of coronary stents for percutaneous treatment of coronary artery disease became common practice., ${ }^{2,3}$ A major drawback of these coronary stents was angiographic in-stent restenosis (ISR) caused by increased neo-intimal hyperplasia (NIH), which led to recurrent ischaemic symptoms and repeat revascularizations in up to $25 \%$ of patients after stent implantation. ${ }^{4}$ Coronary stents were therefore further improved by drug elution from a polymer coating. Drug-eluting stents (DES), compared with coronary stents without an antiproliferative drug coating (nowadays referred to as 'bare metal stents' [BMS]), reduced $\mathrm{NIH}$, thereby reducing the need for repeat revascularizations. ${ }^{5}$ The downside of these first-generation DES was the increased incidence of very late stent thrombosis. ${ }^{.}$This could be explained by delayed and/or incomplete endothelialization and hypersensitivity response to the polymer coating with inflammation of the endothelium. To reduce the rate of very late stent thrombosis, second-generation DES were developed with biocompatible and biodegradable polymers, or even polymer free?

Although the above-mentioned developments led to major improvements in clinical outcomes, manufacturers are still advancing DES. Besides the polymer and antiproliferative drug used, the metallic backbone of DES is an attractive target for further development. The metallic backbone plays a crucial role in device handling, but also safety and efficacy. This narrative review aims to elucidate the role of the metallic backbone on DES performance, with a specific focus on the stent strut thickness. Recent stents with ultrathin stent struts $(\leq 70 \mu \mathrm{m})$ have been developed to improve clinical outcomes after percutaneous coronary intervention (PCI). We will discuss the potential advantages and disadvantages of (ultra)thin struts and discuss the clinical data available.

\section{Potential advantages of ultrathin struts}

Positive impact of thin struts on early vessel healing

Although the antiproliferative drug of first-generation DES has resulted in less $\mathrm{NIH}$ compared to bare-metal stents, it also impaired vascular healing, resulting in delayed and incomplete endothelialization. In addition, the presence of permanent polymers might contribute to delayed healing due to hypersensitivity reactions. As a result, blood flow is exposed to thrombogenic stent struts, potentially leading to stent thrombosis.? Furthermore, delaying the time needed for complete stent strut endothelialization, i.e. restoration of endothelial continuity, might stagnate vessel healing with consequently increased $\mathrm{NIH}$ formation. ${ }^{8}$ These factors may contribute to developing ISR, but also neo-atherosclerosis, leading to repeat revascularizations. Timely reendothelialization is therefore important.

Preclinical data have shown the impact of strut thickness on vessel healing after stent implantation. In a rabbit denudation model, strut coverage at day 14 was as high as $95 \%$ in the stents with the thinnest struts $(81 \mu \mathrm{m})$ and lower with thicker struts: $88 \%$ in stents with struts of 


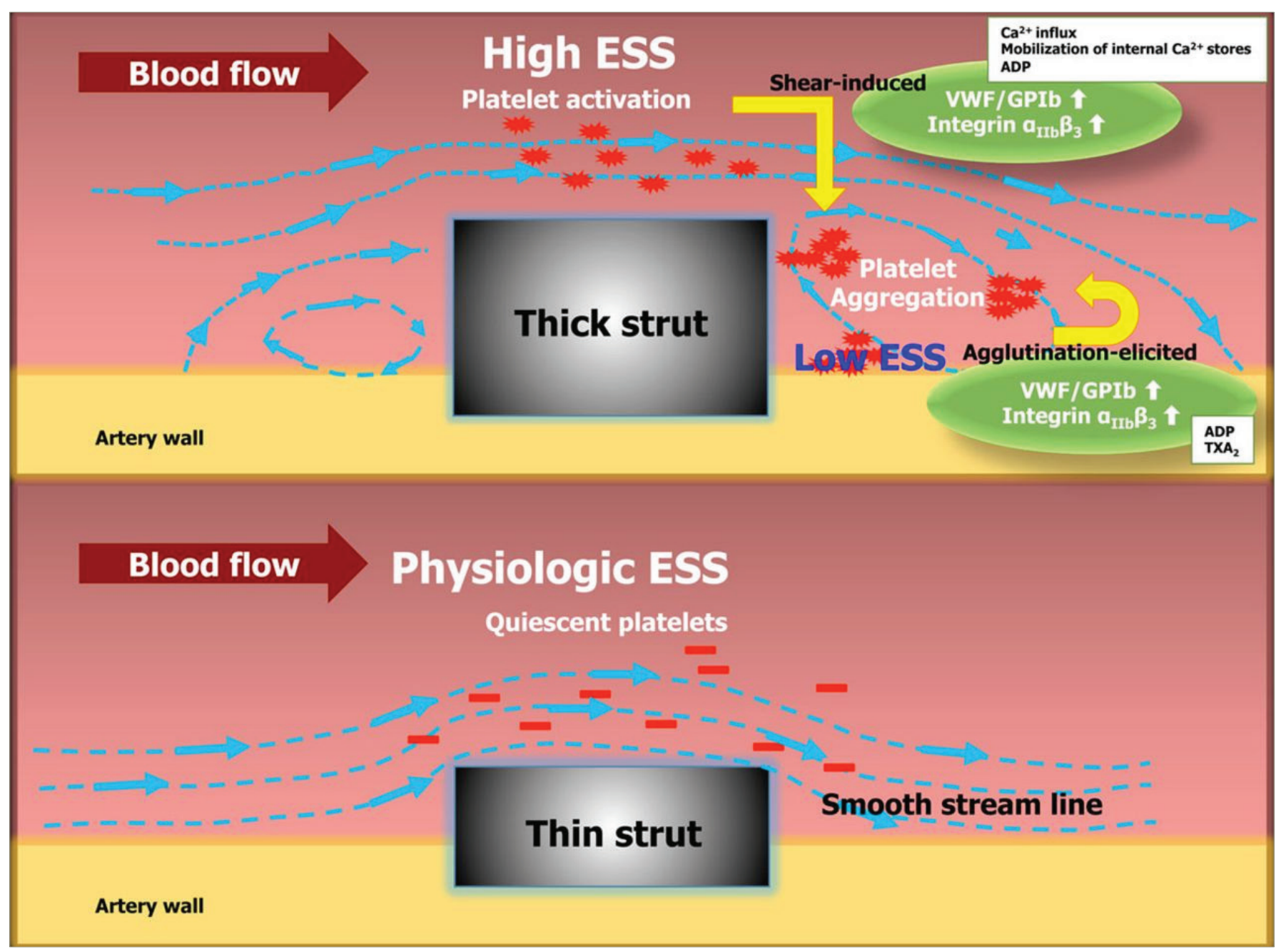

The thick strut disrupts laminar flow leading to flow disturbance and gradients of ESS. Gradients of ESS induce the aggregation and activation of platelets. The thin strut produces less flow disturbance and lower ESS gradients. Reproduced with permission from Sotomi et al, . 2017.12

$A D P=$ adenosine diphosphate; $\mathrm{Ca}^{2+}=$ calcium ions; $\mathrm{ESS}=$ endothelial shear stress; GPIb = glycoprotein Ib; $T X A_{2}=$ thromboxane $\mathrm{A2} ; \mathrm{VWF}=$ Von Willebrand Factor.

$97 \mu \mathrm{m}$ and only $77 \%$ with struts of $132 \mu \mathrm{m} .{ }^{9}$ An in vivo study in a porcine model using optical coherence tomography (OCT) showed faster and better strut coverage of the stent with the thinnest struts $(61 \mu \mathrm{m})$. After 1 week, only $1.6 \%$ of the struts were uncovered in the stent with the $61 \mu \mathrm{m}$ struts, while $6.6 \%$ of struts were uncovered of the stent with the $81 \mu \mathrm{m}$ struts, and as high as $48.4 \%$ of struts were uncovered of the stent with the $141 \mu \mathrm{m}$ struts. ${ }^{10}$ At week 4 , the stent with the thinnest struts showed a mean coverage thickness of $0.14 \mathrm{~mm}$, compared with $0.13 \mathrm{~mm}$ (stent with $81 \mu \mathrm{m}$ struts) and $0.12 \mathrm{~mm}$ (stent with $141 \mu \mathrm{m}$ struts). Delayed endothelialization and increased risk of restenosis with thicker struts might be explained by the larger surface taking more time to endothelialize. Furthermore, thicker struts might cause more vessel injury and local inflammation due to the penetrating stent struts traumatically disrupting the internal elastic lamina. This increased intimal inflammation with thicker struts may promote neo-intimal growth and hyperplasia, leading to restenosis. ${ }^{11}$

Another preclinical study using ex vivo flow loops showed that stents with a strut thickness of $162 \mu \mathrm{m}$ compared with otherwise identical stents with strut thickness of $81 \mu \mathrm{m}$ were 1.5 times more thrombogenetic. ${ }^{10}$ In the same study, both stents were implanted in porcine coronary arteries, showing more thrombus and fibrin deposition 3 days after implantation in the thick-strut stent. It has been postulated that strut thickness modulates local blood flow, with local stagnation and recirculation of blood flow in thick struts (Figure 1). ${ }^{12}$ This leads to areas of lower endothelial shear stress (ESS). ${ }^{13}$ Areas of lower ESS are more prone to platelet aggregation (hence thrombosis), but also determine neo-intima formation. ${ }^{14}$

How does the above affect clinical outcomes in patients treated with coronary stents? Earlier clinical data from the ISAR-STEREO trial showed the influence of strut thickness on ISR rates. A total of 651 patients were randomized to receive a thin-strut stent $(50 \mu \mathrm{m})$ or an otherwise comparable stent with strut thickness of $140 \mu \mathrm{m}$, both without a polymer or antiproliferative drug. ${ }^{.5}$ Incidence of angiographic restenosis (defined as $>50 \%$ stenosis at 6-month follow-up angiography) was almost twice as high in the thick-strut group compared with the thin-strut group (15.0\% versus $25.8 \%$, respectively; relative risk, 0.58; 95\% confidence interval [Cl], 0.39-0.87; $p=0.003$ ). This resulted in differences in clinical restenosis rates, with a repeat intervention performed in $8.6 \%$ in the thin-strut group and $13.8 \%$ in the thick-strut group (relative risk, $0.62 ; 95 \% \mathrm{Cl}, 0.39-0.99 ; \mathrm{p}=0.03$ ). This proves the direct influence of strut thickness on the risk of ISR, with thinner struts decreasing the risk of angiographic and clinical restenosis (although the latter might be partly driven by the 'occulo-stenotic reflex'). ${ }^{16}$ We have observed similar findings in an observational study from our own 
Figure 2: Stent designs of the four ultrathin-strut drug-eluting stents available and their main comparator in clinical trials (the Xience ${ }^{\mathrm{TM}}$ everolimus-eluting stent)

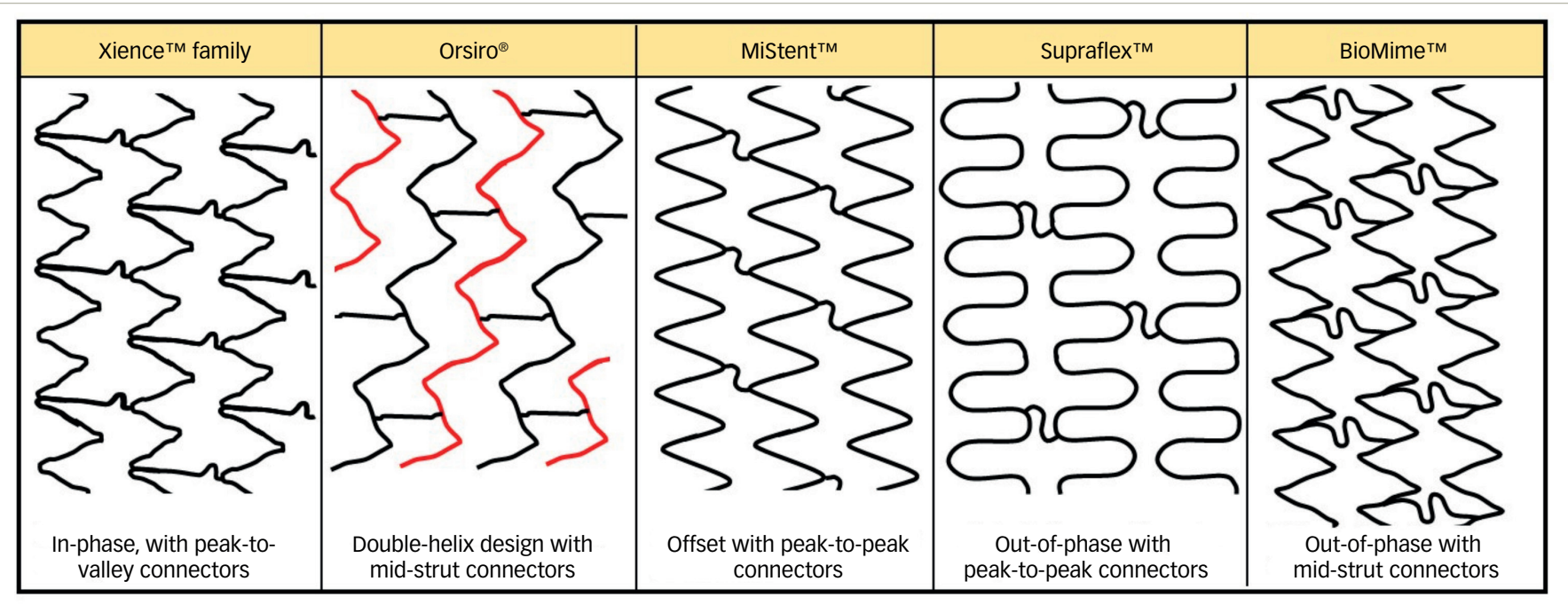

Schematic characterization of the stent designs. The red and black lines on the Orsiro drug-eluting stent illustrate the double helices strut design.

institution. ${ }^{17}$ A meta-regression analysis of DES showed a correlation between strut thickness and 'late lumen loss' more than $0.50 \mathrm{~mm}$, an angiographic outcome that predicts repeat revascularization..$^{18}$ Finally, strut thickness has been conversely associated with stent thrombosis, i.e. stents with thinner struts are less prone to stent thrombosis compared to conventional second-generation DES. ${ }^{19}$

In summary, preclinical data have shown improved vessel healing and less thrombogenicity with thinner struts compared with thicker struts. Clinical data from a meta-analysis have shown that thinner struts may lead to improved clinical outcomes.

\section{Positive impact of ultrathin struts on the mechanical properties and deliverability of drug-eluting stents}

The mechanical behaviour of stents is important for each of the stent 'life phases', which could be categorized as 1) manufacturing and packaging; 2) delivery; 3) deployment; and 4) in vivo function. ${ }^{20}$ Although studies on deployment and especially in vivo function (i.e. angiographic, intravascular imaging and clinical outcome data) are countless, data on mechanical behaviour during delivery of the stent are sparse. Deliverability is characterized by the pushability, trackability and crossability of the stent delivery system, and varies among DES. ${ }^{20,21}$ Although, to the best of our knowledge, no formal tests have been published on deliverability parameters of stents with ultrathin struts, ultrathin struts are presumably more flexible, improving trackability, and have a lower profile, improving crossability compared to conventional second-generation DES.

\section{Negative impact of ultrathin struts on the mechanical properties of drug-eluting stents}

coronary stents should be able to resist high external pressures to maintain lumen patency. In a healthy coronary artery, this is approximately $200 \mathrm{mmHg}$. In a calcified lesion however, the external pressure on the stent is much higher. Failing to resist the (chronic) external pressure may lead to ISR. ${ }^{22}$ This resistance to this external force is dictated by the stent's radial stiffness, defined as a change in stent diameter due to uniformly applied external radial force, and radial strength, defined as the pressure that permanently deforms the stent. ${ }^{18}$
The type of metal used, strut thickness and architecture of the stent determine radial strength. ${ }^{23}$ Stainless steel has been the primary component of the metallic backbone since the first coronary stents, with $316 \mathrm{~L}$ surgical steel being the most widely used. Cobalt-chromium alloys have brought some advances over stainless steel. Due to a higher elastic modulus and tensile strength, radial strength is better with cobalt-chromium than with stainless steel, which has enabled the use of thinner struts without compromising the radial strength. ${ }^{20}$ The most commonly used cobalt-chromium alloy is L605. Alternatively, platinum-chromium platforms have been developed by adding platinum to $316 \mathrm{~L}$ stainless steel, with comparable mechanical properties to cobalt-chromium, also allowing the use of thinner struts. ${ }^{24}$

Stent architecture also affects radial strength..$^{25}$ Current stent architecture can be sub-classified into four categories: coils, slotted tubes, helical and modular designs. Most contemporary stents are modular, consisting of undulated rings. These rings (or 'hoops') are fused together by 'connectors', which provide the longitudinal support of the stent. The number of connectors between two rings, and their orientation, plays a major role in the mechanical properties of coronary stents. The more connectors, the smaller the 'stent cell' (defined as the area enclosed by two connectors and two adjacent rings), which results in a closed-cell design. On the other hand, having fewer connectors results in larger stent cells and an open-cell design. A closed-cell design provides better vessel wall coverage with less prolapse of plaque compared with an open-cell design. ${ }^{25}$ In one animal model, better coverage with less prolapse of plaque resulted in a smoother luminal contour and less platelet activation. ${ }^{26}$ Better coverage with less thrombus protrusion resulted in less distal embolization in patients with ST-elevation myocardial infarction (STEMI). ${ }^{27}$ Closed-cell designs also provide better radial strength than open-cell designs. However, open-cell designs have better flexibility, deliverability and conformability than closed-cell designs. Moreover, they provide easier access to side branches in bifurcation lesions (Figure 2). ${ }^{28}$

Low radial strength may result in stent recoil. Acute stent recoil is defined as a difference in diameter of the stent delivery balloon at the highest used pressure during implantation and the actual measured mean luminal stent diameter after implantation. Acute stent recoil results in residual stenosis associated with ISR and repeat revascularization. ${ }^{15}$ In 
Table 1: Overview of currently available stents with ultrathin struts

\begin{tabular}{|c|c|c|c|c|c|c|c|c|c|}
\hline Stent name & Manufacturer & Material & $\begin{array}{l}\text { Strut } \\
\text { thickness } \\
(\mu \mathrm{m})\end{array}$ & $\begin{array}{l}\text { Coating } \\
\text { thickness } \\
(\mu \mathrm{m})\end{array}$ & Drug used (dose) & Drug coating & Cell design & Polymer & $\begin{array}{l}\text { Drug release } \\
\text { kinetics }\end{array}$ \\
\hline Orsiro $^{\circledR}$ & Biotronik & $\begin{array}{l}\text { Cobalt- } \\
\text { chromium }\end{array}$ & 60 & $\begin{array}{l}\text { Abluminal } \\
7.5, \text { luminal } \\
3.5\end{array}$ & $\begin{array}{l}\text { Sirolimus } \\
\left(1.4 \mu \mathrm{g} / \mathrm{mm}^{2}\right)\end{array}$ & $\begin{array}{l}\text { Circumferential } \\
\text { (asymmetrical) }\end{array}$ & Open & $\begin{array}{l}\text { Amorphous } \\
\text { silicon } \\
\text { carbide } \\
\text { coating and } \\
\text { BIOlute }{ }^{\circledR} \text { PLLA }\end{array}$ & $\sim 100$ days \\
\hline MiStent $^{T M}$ & Micell & $\begin{array}{l}\text { Cobalt- } \\
\text { chromium }\end{array}$ & 64 & $\begin{array}{l}\text { Abluminal } \\
\text { 15, luminal } 5\end{array}$ & $\begin{array}{l}\text { Sirolimus } \\
\left(2.44 \mu \mathrm{g} / \mathrm{mm}^{2}\right)\end{array}$ & $\begin{array}{l}\text { Circumferential } \\
\text { (asymmetrical) }\end{array}$ & Open & PLGA & $\begin{array}{l}50 \% \text { at } 30 \text { days, } \\
\text { complete at } \\
9 \text { months }\end{array}$ \\
\hline $\begin{array}{l}\text { BioMime }^{\text {TM} /} \\
\text { BioMime }^{\text {TM }} \\
\text { Morph }\end{array}$ & Meril & $\begin{array}{l}\text { Cobalt- } \\
\text { chromium }\end{array}$ & 65 & 2 & $\begin{array}{l}\text { Sirolimus } \\
\left(1.25 \mu g / \mathrm{mm}^{2}\right)\end{array}$ & Circumferential & $\begin{array}{l}\text { Open and } \\
\text { closed }\end{array}$ & PLLA + PLGA & $\sim 98 \%$ at 30 days \\
\hline Supraflex TM/ & Sahajanand & $\begin{array}{l}\text { Cobalt- } \\
\text { chromium }\end{array}$ & 60 & $5-6$ & $\begin{array}{l}\text { Sirolimus } \\
\left(1.4 \mu \mathrm{g} / \mathrm{mm}^{2}\right)\end{array}$ & Circumferential & Open & $\begin{array}{l}\text { PLLA + PLGA } \\
+ \text { PVP }\end{array}$ & $\begin{array}{l}70 \% \text { at } 7 \text { days, } \\
\text { complete at } \\
48 \text { days }\end{array}$ \\
\hline $\begin{array}{l}\text { Supraflex } \\
\text { Cruz }\end{array}$ & Sahajanand & $\begin{array}{l}\text { Cobalt- } \\
\text { chromium }\end{array}$ & 60 & $5-6$ & $\begin{array}{l}\text { Sirolimus } \\
\left(1.4 \mu \mathrm{g} / \mathrm{mm}^{2}\right)\end{array}$ & Circumferential & Open & $\begin{array}{l}\text { PLLA, PLCL, } \\
\text { PVP }\end{array}$ & $\begin{array}{l}80 \% \text { at } 28 \text { days, } \\
\text { complete at } \\
\sim 90 \text { days }\end{array}$ \\
\hline Tetriflex ${ }^{\mathrm{TM}}$ & Sahajanand & $\begin{array}{l}\text { Cobalt- } \\
\text { chromium }\end{array}$ & 60 & $4-6$ & $\begin{array}{l}\text { Sirolimus } \\
\left(1.4 \mu \mathrm{g} / \mathrm{mm}^{2}\right)\end{array}$ & Circumferential & Open & $\begin{array}{l}\text { PLLA, 50/50 } \\
\text { PDLGA, PVP }\end{array}$ & $\begin{array}{l}80 \% \text { at } 28 \text { days, } \\
\text { complete at } \\
\sim 90 \text { days }\end{array}$ \\
\hline Tetrilimus ${ }^{\top M}$ & Sahajanand & $\begin{array}{l}\text { Cobalt- } \\
\text { chromium }\end{array}$ & 60 & $4-6$ & $\begin{array}{l}\text { Everolimus } \\
\left(1.0 \mu \mathrm{g} / \mathrm{mm}^{2}\right)\end{array}$ & Circumferential & Open & $\begin{array}{l}\text { PLLA, PLCL, } \\
\text { PVP }\end{array}$ & $\begin{array}{l}80 \% \text { at } 28 \text { days, } \\
\text { complete at } \\
\sim 90 \text { days }\end{array}$ \\
\hline Everoflex ${ }^{\top M}$ & Sahajanand & $\begin{array}{l}\text { Cobalt- } \\
\text { chromium }\end{array}$ & 60 & $5-6$ & $\begin{array}{l}\text { Everolimus } \\
\left(1.0 \mu \mathrm{g} / \mathrm{mm}^{2}\right)\end{array}$ & Circumferential & Open & $\begin{array}{l}\text { PLLA, PLCL, } \\
\text { PVP }\end{array}$ & $\begin{array}{l}70 \% \text { at } 7 \text { days, } \\
\text { complete at } 48 \text { days }\end{array}$ \\
\hline
\end{tabular}

PDLGA = poly(D,Llactidecoglycolide); $P L C L=$ poly-L-lactide-co-caprolactone; $P L G A=$ poly-lactic-co-glycolic acid; PLLA = poly-L-lactic acid; $P V P=$ poly-vinyl pyrrolidone.

the BIOFLOW-II trial (NCT01356888), 452 patients were randomized 2:1 to Orsiro ${ }^{\circledR}$ sirolimus-eluting stent (Biotronik, Buelach, Switzerland) with biodegradable polymer on ultrathin struts $(60 \mu \mathrm{m})$ or Xience ${ }^{\mathrm{TM}}$ everolimus-eluting stent (Abbott Vascular, Santa Clara, CA, USA) with durable polymer on thin struts $(81 \mu \mathrm{m})$. In a subgroup of 56 patients, intravascular ultrasound data immediately and 9 months post-stent implantation showed similar stent areas. ${ }^{29}$ On the other hand, an observational study in 128 patients undergoing $\mathrm{PCl}$ for chronic total occlusions (CTOS) showed higher absolute (as measured in $\mathrm{mm}$ ) and relative stent (as measured in \%) recoil with the ultrathin-strut Orsiro stent compared with the $81 \mu \mathrm{m}$ strut Resolute Onyx ${ }^{\mathrm{TM}}$ zotarolimuseluting stent (Medtronic Cardiovascular, Santa Rosa, CA, USA)..$^{30}$ The randomized PRISON IV trial, comparing the Orsiro stent with the Xience stent in patients treated for CTOs, failed to show non-inferiority of the Orsiro ultrathin stent in terms of in-segment late lumen loss, with a statistically higher rate of binary restenosis in the Orsiro group. ${ }^{31}$

To summarize, the type of metal used, strut thickness and architecture of the stent determine radial strength. Although thinner struts made of cobalt-chromium or platinum-chromium alloys have a radial strength comparable to those made with stainless steel, some clinical data suggest that the radial strength of stents with ultrathin struts might be insufficient for treating CTO lesions and might lead to more stent recoil compared to conventional second-generation DES. More studies are necessary, exploring other lesions (such as highly calcified lesions) in which a higher radial strength is likely needed.

\section{Overview of currently available stents with ultrathin struts}

Thin struts are arbitrarily defined as being $<100 \mu \mathrm{m}$ thick, whereas ultrathin struts are $<70 \mu \mathrm{m}$ thick. An overview of stents with ultrathin struts is given in Table 1, and is discussed below.

\section{Orsiro}

The Orsiro stent has a $60 \mu \mathrm{m}$ strut thickness ( $80 \mu \mathrm{m}$ when stent diameter $>3 \mathrm{~mm}$ ). The stent is made of a cobalt-chromium alloy and it elutes sirolimus from a biodegradable polymer, poly-L-lactic acid (PLLA). The polymer coverage is asymmetrical, with a thicker coating (and thus more drug release) on the abluminal side of the struts. The sirolimus is eluted over approximately 100 days. The design of the stent is different from other DES; whereas most DES have adjacent rings fused together by connectors, the Orsiro consists of two double helices (instead of separate rings), which are held together by connectors oriented in the mid-portion of each strut (Figure 2).

\section{MiStent}

The MiStent ${ }^{\mathrm{TM}}$ stent (Micell Technologies, Durham, NC, USA) has a 64 $\mu \mathrm{m}$ strut thickness and is made of a cobalt-chromium alloy. The stent coating consists of a poly-lactic-co-glycolic acid (PLGA) polymer loaded with microcrystalline particles of sirolimus. The coating is asymmetrical, with a thicker coating on the abluminal side $(\sim 15 \mu \mathrm{m})$ than on the luminal side $(\sim 5 \mu \mathrm{m})$ of the struts. The coating process of dry-powder crystalline sirolimus is solvent free and further differentiated by supercritical fluid 
technology to apply the polymer component. While the polymer fully biodegrades within 3 months, the sirolimus remains in the surrounding tissue for up to 9 months to continuously inhibit neointimal tissue growth. The stent design consists of rings each connected by three interconnectors in an 'off-set' peak-to-peak fashion (Figure 2).

\section{Supraflex ${ }^{\mathrm{TM}}$}

The Supraflex ${ }^{\mathrm{TM}}$ stent (Sahajanand Medical Technologies, Mumbai, India) is made from L605 cobalt-chromium alloy, and elutes sirolimus from a biodegradable polymer. The biodegradable polymer is a matrix coating consisting of PLLA with a 50:50 mixture of poly(D,Llactidecoglycolide) (PDLGA) and poly-vinyl pyrrolidone (PVP). The average polymer coating is 5-6 $\mu \mathrm{m}$ thick, and the polymer degrades gradually over 9-12 months. The stent strut thickness is $60 \mu \mathrm{m}$. Sirolimus is released over a short period of 48 days. The stent design consists of rings connected by two highly flexible S-link connectors (Figure 2). Sahajanand Medical Technologies also developed the Everoflex ${ }^{\mathrm{TM}}$ stent, comparable to Supraflex but with everolimus as the anti-proliferative drug. In addition, they developed the Supraflex ${ }^{\mathrm{TM}}$ Cruz stent, which is similar to the Supraflex except for the connectors between the rings and a different polymer coverage (Table 1). The Supraflex Cruz uses long dual Z (LDZ) links, which are best described as in-phase valley-to-valley connections. Moreover, the company also manufactures the Tetriflex ${ }^{\top \mathrm{M}}$ stent, similar in design to the Supraflex Cruz but with different polymers used (three separate thin layers of biodegradable polymer). Finally, the Tetrilimus ${ }^{\mathrm{TM}}$ stent has a comparable stent design to the Tetriflex stent design, with three layers of polymer, but with everolimus as the anti-proliferative drug.

\section{BioMime $^{\mathrm{TM}}$}

The BioMime ${ }^{\text {TM }}$ stent (Meril Life Sciences, Vapi, India) is made from L605 cobalt-chromium alloy, and elutes sirolimus from the biocompatible and bioabsorbable polymers PLLA and PLGA. The coating is uniformly thin $(2 \mu \mathrm{m})$, and degrades in approximately 6-9 months. The stent strut thickness is $65 \mu \mathrm{m}$. The stent design is a unique hybrid design of closed cells at the edges and an open-cell design in the mid-segment. The adjacent rings are connected with Y-connectors in the mid-portion of the struts connected to each other by S-links (Figure 2). The company also developed the BioMime Morph'⿳一 stent, with stent lengths up to $60 \mathrm{~mm}$ with a tapered design, which is suitable for long lesions in tapered vessels, avoiding multiple stent uses with multiple overlap. In addition, they also developed the BioMime Branch ${ }^{\mathrm{TM}}$ stent, a dedicated bifurcation stent with ultrathin struts eluting sirolimus.

\section{Clinical data on stents with ultrathin struts}

Although strut thickness is likely to influence clinical outcomes of PCl, it is impossible to disentangle the sole effect of reduced strut thickness from that of other stent components. As outlined earlier, the stent design, polymer and anti-proliferative drug are also essential factors that determine outcome. In this section, we will provide an overview of clinical data available for ultrathin-strut DES. These other factors must be considered when interpreting trial results and clinical outcomes.

\section{Orsiro}

The Orsiro stent is the most widely investigated ultrathin-strut stent available. In the BIOFLOW-II trial (NCT01356888), 452 patients from eight European countries were randomized 2:1 to the Orsiro $(\mathrm{N}=298)$ or Xience $(\mathrm{N}=154)$ stent, an everolimus-eluting stent with durable polymer and $81 \mu \mathrm{m}$ strut thickness. ${ }^{29}$ Lesion length had to be $<26 \mathrm{~mm}$ and main exclusion criteria were recent myocardial infarction (Ml; $<72$ hours), unprotected left main coronary artery disease, three-vessel coronary artery disease and left ventricular ejection fraction $<30 \%$.
The study showed non-inferiority of the Orsiro stent compared with the Xience stent with regard to 'in-stent late loss' at 9-month re-angiography $(0.10 \pm 0.32 \mathrm{~mm}$ (mean $+\mathrm{SD})$ versus $0.11 \pm$ $0.29 \mathrm{~mm}$, respectively; $\mathrm{p}$ for non-inferiority $<0.001$ ). In the multicentre, intercontinental BIOFLOW-IV trial (NCT01939249), 575 patients were randomized 2:1 to the Orsiro or Xience stents. ${ }^{32}$ Inclusion and exclusion criteria were similar to those of BIOFLOW-II. The non-inferiority primary endpoint of target vessel failure (composite of cardiac death, target-vessel Ml, emergent coronary artery bypass graft and clinically driven target-vessel revascularization [TVR]) at 12 months was met: $5.5 \%$ in the Orsiro group versus $7.5 \%$ in the Xience group ( $p$ for noninferiority <0.001). The BIOFLOW-V trial (NCT02389946) included 1,334 patients (from 13 countries in Asia, Europe and North America) who were randomized to Orsiro or Xience in a 1:1 fashion. ${ }^{33}$ Patients with up to two-vessel coronary artery disease were included, as well as those with non-ST segment elevation acute coronary syndrome (NSTE-ACS), if haemodynamically stable. Maximum lesion length was $36 \mathrm{~mm}$. CTOs, bifurcation lesions, bypass graft lesions and ISR lesions of previous DES were not allowed. The primary endpoint was target-lesion failure (TLF; composite of cardiac death, target-vessel $\mathrm{Ml}$ and ischaemia-driven TLR) at 2 years, which was significantly lower in the Orsiro group than the Xience group ( $7.5 \%$ versus $11.9 \%$, respectively; $p=0.015$ ); this was mainly driven by a lower rate of target-vessel $\mathrm{Ml}(5.3 \%$ versus $9.5 \%$; $\mathrm{p}=0.01)$ and stent thrombosis $(0.1 \%$ versus $1.0 \% ; \mathrm{p}=0.045)$ in the Orsiro group..$^{33}$ Extended follow-up to 3 years showed similar findings: TLF was $8.2 \%$ for Orsiro and $13.6 \%$ for Xience $(p=0.002)$, driven by lower targetvessel $\mathrm{MI}(5.0 \%$ versus $9.2 \% ; \mathrm{p}=0.003)$ and clinically driven TLR rates (3.2\% versus $6.7 \% ; p=0.006$ ) in the Orsiro group. Definite/probable late or very late stent thrombosis rate was also significantly lower in the Orsiro group than the Xience group $(0.1 \%$ versus $1.2 \%$, respectively; $\mathrm{p}=0.018){ }^{34}$ In the BIOFLOW-VI (NCT01939249) randomized trial, 440 patients from 11 Chinese sites were randomized 1:1 to Orsiro or Xience. ${ }^{35}$ Up to two separate lesions were allowed, with a lesion length $<36 \mathrm{~mm}$ and a target-vessel Thrombolysis In Myocardial Infarction (TIMI) flow grade of 2 or higher. Patients with previous MI within 7 days, left ventricular ejection fraction below $40 \%$, left main stenosis, bifurcations with side branch of $2.5 \mathrm{~mm}$ or larger, or heavily thrombotic or calcified lesions were excluded. The study showed that Orsiro was non-inferior to Xience with regard to 9-month late lumen loss (mean difference $-0.02 \mathrm{~mm}$; p for non-inferiority $<0.0001$ ).

In the BIOSCIENCE trial (NCT01443104), 2,119 patients from nine centres in Switzerland were randomized to Orsiro or Xience. ${ }^{36}$ The trial had an 'all-comers' design with minimal exclusion criteria, allowing patients with acute coronary syndromes (53\%), diabetes (24\%), history of hypertension (68\%) or renal failure (15\%) to participate. There were no restrictions on number of lesions, number of vessels treated and lesion length. Both de novo and restenotic lesions in bypass grafts or previous stents were eligible. The primary endpoint was TLF (composite of cardiac death, target-vessel $\mathrm{MI}$ and clinically indicated TLR) at 12 months. The study showed non-inferiority of Orsiro with regard to this primary endpoint (6.5\% versus 6.6\%; p for non-inferiority $<0.004)$. A significant interaction was found for the pre-specified stratified analyses of the primary endpoint favouring Orsiro in patients presenting with STEMI at 12 months (3.3\% versus $8.7 \%$, RR $0.38,95 \% \mathrm{Cl} 0.16-0.91, \mathrm{p}=0.024$, $\mathrm{p}$ for interaction=0.014). Long-term (5 years) follow-up showed similar clinical outcomes in both groups. ${ }^{37}$

In the subsequent BIOSTEMI trial (NCT02579031), 1,300 patients presenting with STEMI were randomized in a 1:1 fashion to Orsiro or Xience. The primary endpoint of non-inferiority with regard to TLF 
(composite of cardiac death, Ml and TLR) was met. TLF rates were, indeed, lower in patients treated with Orsiro compared with Xience; 38,39 TLF occurred in $5.1 \%$ in the Orsiro group and $8.6 \%$ in the Xience group at 2 years. At 2 years there was a statistically significant difference in TLR in favour of Orsiro (2.5\% versus $5.1 \%) .^{38}$

The SORT OUT VII trial (NCT01879358) was an all-comer (21\% STEMI, $31 \%$ NSTE-ACS, $19 \%$ diabetes, $58 \%$ history of hypertension, $57 \%$ hypercholesterolaemia, 22\% multi-vessel PCl, 4\% CTO, 12\% bifurcations), investigator-initiated, randomized controlled trial comparing the Orsiro stent with the Noboriтm stent (Terumo Corporation, Tokyo, Japan) in 2,525 patients from Denmark. ${ }^{40}$ The Nobori stent is comparable with Orsiro by eluting an antiproliferative drug (biolimus) from a biodegradable polymer (poly-D,L-lactic acid [PDLLA]). The major difference from Orsiro is its stent design (rings connected by two connectors) and its thicker struts $(120 \mu \mathrm{m}){ }^{40}$ In SORT OUT VII, the primary endpoint was TLF (composite of cardiac death, $\mathrm{Ml}$ and TLR) at 12 months. At 12 months, the primary endpoint occurred in $3.8 \%$ in the Orsiro group and $4.6 \%$ in the Nobori group ( $p$ for non-inferiority $<0.0001$ )..$^{40}$ The Orsiro stent was superior in terms of definite stent thrombosis $(0.4 \%$ versus $1.2 \% ; p=0.034)$, mostly due to difference in sub-acute stent thrombosis (i.e. stent thrombosis occurring between 24 hours and 30 days). At 3-year follow-up, clinical outcomes were comparable between the two stents, including definite stent thrombosis rates (1.0\% versus $1.7 \% ; 95 \% \mathrm{Cl}, 0.30-1.18) .{ }^{41}$

In the SORT OUT IX all-comers trial (NCT02623140), the BioFreedom ${ }^{\mathrm{TM}}$ stent (Biosensors Interventional Technologies, Singapore) was compared with the Orsiro stent. ${ }^{42}$ The BioFreedom stent is a stainless-steel stent with a strut thickness of $120 \mu \mathrm{m}$, and is coated with Biolimus A9TM without a polymer. ${ }^{42}$ A total of 3,151 patients, included from three centres in Denmark, were randomized 1:1 to BioFreedom or Orsiro. In the total cohort, $24 \%$ of patients presented with STEMI and $29 \%$ with NSTE-ACS; $19 \%$ had diabetes, $59 \%$ had a history of hypertension and $55 \%$ had hypercholesterolaemia; and 23\% underwent multi-vessel PCl, 5\% underwent $\mathrm{PCl}$ for $\mathrm{CTO}$, and 19\% underwent PCI for a bifurcation lesion. The primary endpoint was the composite of cardiac death, target lesionrelated $\mathrm{MI}$ or TLR at 1 year. At 1 year, the primary endpoint occurred in $5.0 \%$ of the BioFreedom group and $3.7 \%$ of the Orsiro group, not meeting the criteria for non-inferiority for the BioFreedom stent compared with the Orsiro ( $p$ for non-inferiority $=0.14$ ). TLR rate was significantly higher in the BioFreedom group than the Orsiro group (3.5\% versus $1.3 \%$, respectively; $p<0.0001) .42$

In the SORT OUT X trial (NCT03216733), the $\mathrm{COMBO}^{\circledR}$ stent (OrbusNeich Medical, Hoevelaken, The Netherlands) was compared with the Orsiro stent. ${ }^{43}$ The COMBO stent has a 316-L stainless-steel platform, with strut thickness of $100 \mu \mathrm{m}$, eluting sirolimus from a biocompatible, biodegradable coating of urethane-linked lactide-glycolide multiblock co-polymers, which is on the abluminal site only. In addition, a layer of murine, monoclonal, anti-human CD34+ antibodies is attached to this matrix to promote rapid endothelialization. The SORT OUT X trial had an all-comer design, which included 3,146 patients with STEMI (24\%), NSTE-ACS (29\%), diabetes (17\%), history of hypertension (54\%) and hypercholesterolaemia (50\%). ${ }^{43}$ In total, $26 \%$ of patients underwent multivessel $\mathrm{PCl}, 4 \%$ underwent $\mathrm{PCl}$ for $\mathrm{CTO}$ and $24 \%$ had $\mathrm{PCl}$ for a bifurcation lesion. The primary endpoint was a composite of cardiac death, $\mathrm{Ml}$ and TLR rate at 12 months. The non-inferiority criteria were not met for the COMBO stent, and the primary endpoint occurred in $6.3 \%$ of the COMBO stent group and $3.7 \%$ of the Orsiro stent group ( $p$ for non-inferiority=0.76). There were significantly more TLRs with the COMBO stent compared with the Orsiro stent ( $3.4 \%$ versus $1.5 \%$, respectively; $p=0.0012$ ). ${ }^{43}$
BIO-RESORT (NCT01674803) was an investigator-initiated trial of 3,514 patients (included from four Dutch sites) randomized to the Orsiro stent, the Synergy ${ }^{\top \mathrm{M}}$ stent (Boston Scientific, San Jose, CA, USA) or the Resolute Integrity ${ }^{\top \mathrm{TM}}$ stent (Medtronic Cardiovascular, Santa Rosa, CA, USA) ${ }^{44}$ The Synergy stent is made from a platinum-chromium alloy, elutes everolimus from a biodegradable PLGA polymer and has a strut thickness of $74 \mu \mathrm{m}$. The Resolute Integrity stent is made from a cobalt-chromium alloy, has a strut thickness of $91 \mu \mathrm{m}$ and elutes zotarolimus from a BioLinx ${ }^{\mathrm{TM}}$ polymer coverage made from a blend of three polymers: the hydrophobic C10 polymer, aiding in drug-release control; the hydrophilic C19 polymer, supporting biocompatibility; and PVP, increasing initial drug burst and enhancing elution rate. The trial had an all-comers design: acute and stable coronary syndromes were allowed, as were de novo and restenotic lesions, and both coronary and bypass lesions were permitted. The primary endpoint was a composite of cardiac death, MI and TVR at 12 months and was $5.0 \%$ in all three groups ( $p$ for non-inferiority $<0.0001)$. Definite stent thrombosis rates were extremely low $(0.3 \%$ in all three groups). ${ }^{44}$ Three-year follow-up data showed similar target-vessel failure rates among groups: $8.5 \%$ in the Orsiro group, $8.8 \%$ in the Synergy group and $10.0 \%$ in the Resolute Integrit group. ${ }^{45} \mathrm{All}$ other clinical endpoints were similar between the three stents, including low definite/probable stent thrombosis rates of $1.1 \%$ (Orsiro and Synergy) and $0.9 \%$ (Resolute Integrity). ${ }^{45}$

The ORIENT trial (NCT01826552) was a randomized controlled trial comparing angiographic outcomes with the Orsiro stent and the Resolute Integrity ${ }^{\top M}$ stent in 372 patients in eight centres in South Korea. ${ }^{46}$ Both stable coronary artery disease (53\%) and acute coronary syndromes (13\% non-STEMl; 9\% STEMI) were allowed indications for PCI. There were no restrictions on lesion complexity; left main coronary artery disease (5\%), CTOS (8\%), bifurcation lesions (23\%) and restenotic lesions (2\%), among others, were allowed. The primary endpoint was non-inferiority for in-stent late lumen loss at 9-month follow-up. Orsiro was non-inferior to Resolute Integrity (median late lumen loss was $0.06 \mathrm{~mm}$ and $0.12 \mathrm{~mm}$, respectively; p for non-inferiority $<0.001$; $p$ for superiority $=0.205$ ). ${ }^{46}$ Regarding the TLF endpoint (composite of cardiac death, target-vessel MI and TLR), clinical outcomes were comparable between the Orsiro and Resolute Integrity groups (2.4\% versus $3.3 \%$, respectively); however, the study was not adequately powered for clinical endpoints. Three-year clinical follow-up showed TLF rates of $4.7 \%$ (Orsiro) and $7.8 \%$ (Resolute Integrity) ( $p=0.232$ by log-rank test). ${ }^{47}$ Stent thrombosis occurred in no patients in the Orsiro group and two patients in the Resolute integrity group $(0.0 \%$ versus $1.6 \%$, respectively; $p=0.040) .{ }^{47}$

In the BIONYX all-comers trial (NCT02508714), the Resolute OnyX stent was compared with the Orsiro stent in 2,488 patients. ${ }^{48}$ The Resolute Onyx is made from a single sinusoid-form wire with a platinum-iridium core within a cobalt alloy shell, which is automatically welded at predefined connecting sites. It elutes zotarolimus from a durable polymer with a strut thickness of $81 \mu \mathrm{m} .{ }^{49}$ Patients with acute coronary syndrome and stable coronary artery disease were included: 25\% presented with STEMI, 26\% with NSTE-ACS, $21 \%$ had diabetes, $52 \%$ had a history of hypertension, $46 \%$ had hypercholesterolaemia, $8 \%$ had previous stroke, $7 \%$ had renal insufficiency, $18 \%$ underwent multi-vessel $\mathrm{PCl}, 5 \%$ underwent $\mathrm{PCl}$ for СTO and $39 \%$ had $\mathrm{PCl}$ for a bifurcation lesion. The primary endpoint (non-inferiority for target vessel failure [TVF], defined as a composite of cardiac death, target vessel-related MI or clinically indicated TVR, at 12 months) was met, and occurred in $4.5 \%$ of the Orsiro group and $4.7 \%$ of the Resolute Onyx group. ${ }^{48}$ Three-year follow-up showed similar results with no significant differences in TVF (9.2\% versus $8.9 \%$ in Resolute Onyx and Orsiro, respectively; $p=0.85) . .^{50}$ 
In the multicentre, all-comers BIODEGRADE trial (NCT02299011), 2,341 patients were randomized to the Orsiro stent or the first-generation BioMatrix ${ }^{\mathrm{TM}} /$ BioMatrix Flex ${ }^{\mathrm{TM}}$ stents (Biosensors Interventional Technologies, Singapore). The BioMatrix stent is made from stainless steel with a strut thickness of $120 \mu \mathrm{m}$, and elutes Biolimus from a poly-lactic acid biodegradable polymer..$^{51}$ In BIODEGRADE, acute coronary syndrome was the most prevalent indication for $\mathrm{PCl}(67 \%)$. More than half of the patients (60\%) had a history of hypertension, $27 \%$ underwent $\mathrm{PCl}$ for more than one target lesion, 5\% underwent PCI for CTO and 15\% had $\mathrm{PCl}$ for a bifurcation lesion. The primary endpoint was TLF (composite of cardiac death, target-vessel MI or ischaemia-driven TLR) at 18 months. The primary endpoint was met and occurred in $2.9 \%$ of the BioMatrix ${ }^{\mathrm{TM}}$ group and $2.1 \%$ of the Orsiro group ( $p$ for non-inferiority $<0.001$ ).

Finally, the above-described PRISON IV trial randomized 330 patients with a CTO, comparing the Orsiro stent with the Xience stent. ${ }^{31}$ The primary non-inferiority endpoint was in-segment late lumen loss at 9 months. Non-inferiority criteria were not met, with a numerically higher late lumen loss with Orsiro than with Xience $(0.13 \mathrm{~mm}$ versus $0.02 \mathrm{~mm}$, respectively; $p$ for non-inferiority $=0.11$ ). Binary restenosis rates were higher in the Orsiro group, leading to a significantly higher TLR rate at 3 years. ${ }^{52}$

In conclusion, the Orsiro stent has been rigorously investigated in multiple randomized controlled trials worldwide and in very diverse populations, including in all-comers and in acute coronary syndrome-specific populations, showing that the Orsiro stent competes with second- and other third-generation DES. ${ }^{29-49}$ Orsiro was non-inferior in all the trials comparing with other contemporary DES (i.e. mainly Xience, but also Resolute, Synergy and BioMatrix), while some other newer DES (e.g. Bioreedom and Combo stents) have not always met noninferiority criteria when compared with Orsiro. In specific subgroups (e.g. STEMI) Orsiro might even be superior to second-generation DES, while in other subgroups (e.g. CTOs) Orsiro may be inferior.

\section{MiStent}

The MiStent stent has been investigated in the DESSOLVE trial programme. DESSOLVE I (NCT01247428) was a first-in-human study including 30 patients with stable or unstable angina pectoris (excluding patients with $\mathrm{MI}$ ) with lesion length $<23 \mathrm{~mm}$ and coronary diameter of 2.5-3.0 mm. Patients with complex type $\mathrm{C}$ lesions (according to the American College of Cardiology/American Heart Association classification) were excluded. The study showed low and stable late lumen loss at 18-month follow-up, with complete struts coverage on OCT and no stent thrombosis. ${ }^{53}$

In the DESSOLVE II trial (NCT01294748), 184 patients were randomized 2:1 to the Mistent stent and the Endeavor ${ }^{\mathrm{TM}}$ zotarolimus-eluting stent (Medtronic Cardiovascular, Santa Rosa, CA, USA) with a biocompatible BioLinX ${ }^{\mathrm{TM}}$ polymer coating and a strut thickness of $91 \mu \mathrm{m} .{ }^{54}$ All patients underwent quantitative coronary angiography directly after implantation (baseline) and during re-angiography at 9-month follow-up. A subgroup was also analysed using OCT. Inclusion and exclusion criteria were similar to DESSOLVE I. The primary endpoint, superiority of MiStent in terms of late lumen loss at 9 months, was met (mean late lumen loss $0.27 \pm 0.46 \mathrm{~mm}$ in 103 patients with the Mistent versus $0.58 \pm 0.41 \mathrm{~mm}$ in 52 patients with the Endeavor; $p<0.001$ ). The proportion of uncovered struts on OCT at 9 months was very low in both groups, but statistically significantly lower in the Endeavor group (2.1\% in Mistent versus $0.5 \%$ in Endeavor; $\mathrm{p}=0.048$ ). ${ }^{54}$ Long-term (5 years) follow-up data from both trials showed comparable clinical outcomes between both stents. The major adverse cardiac event (MACE) rate, defined as a composite of any death, MI or clinically driven TVR, was $15.1 \%$ in the Mistent group versus $22.0 \%$ in the Endeavor group $(p=0.295) .{ }^{67}$ TVR and TLR rates were similar between groups. Definite/probable stent thrombosis rates were low in both groups, but numerically lower in the Mistent group (0.0\% Mistent versus 1.7\% Endeavor). However, DESSOLVE II was not designed for and thus not adequately powered for assessing clinical endpoints. ${ }^{55}$

The DESSOLVE III trial (NCT02385279) was therefore designed and powered to assess clinical endpoints. The DESSOLVE III trial was a multicentre, international, all-comers randomized trial including 1,398 patients throughout Europe. ${ }^{56}$ Patients were randomized 1:1 to either Mistent or Xience. With its all-comers design, acute coronary syndrome and stable coronary artery disease were both allowed indications for PCl: $15 \%$ of patients presented with STEMI, 20\% with non-STEMI, 27\% had diabetes, $74 \%$ had a history of hypertension, $61 \%$ had hypercholesterolaemia, $10 \%$ had established peripheral vascular disease and $7 \%$ had renal insufficiency. Average lesions per patient was 1.5; 7\% had PCl for a bifurcation lesion and $3 \%$ had $\mathrm{PCl}$ for restenotic lesions. The primary endpoint was the non-inferiority of the Mistent regarding a device-oriented composite endpoint of cardiac death, target-vessel MI or clinically indicated TLR at 12 months. At 12 months, the device-oriented outcome had occurred in $5.8 \%$ of the Mistent group and $6.5 \%$ of the Xience group, meeting the non-inferiority criteria ( $p$ for non-inferiority=0.0001). Individual components of the composite endpoint were similar in both groups. Stent thrombosis rates were low and comparable between groups (definite/probable stent thrombosis rates were $0.7 \%$ and $0.9 \%$ in the Mistent and Xience groups, respectively). ${ }^{56}$ Two-year follow-up of the trial showed similar findings. The device-oriented outcomes occurred in $8.7 \%$ in the Mistent group and $8.6 \%$ in the Xience group $(p=0.958) .{ }^{57}$ At 3-year follow-up, the device-oriented composite endpoint occurred in $10.5 \%$ of the Mistent group and $11.5 \%$ of the Xience group $(p=0.55)$. Between the Mistent and Xience groups, cardiac death rates $(3.9 \%$ versus $3.8 \%$, respectively; $\mathrm{p}=0.88$ ), target-vessel $\mathrm{Ml}$ rates $(3.2 \%$ versus $2.5 \%$, respectively; $\mathrm{p}=0.43)$ and clinically indicated TLR rates $(5.2 \%$ versus $6.5 \%$, respectively; $\mathrm{p}=0.30$ ) were not significantly different. Again, definite/probable stent thrombosis was infrequent (1.2\% versus $1.5 \%$, respectively; $\mathrm{P}=0.64)^{58}$

The DESSOLVE trial programme showed the safety and efficacy of the Mistent stent compared with the second-generation Xience stent.

\section{Supraflex ${ }^{\mathrm{TM}}$}

The FLEX Registry showed few adverse clinical outcomes with the Supraflex stent at 12 months. MACE, defined as the composite of cardiac death, $\mathrm{Ml}$ and TVR, occurred in 3.7\% of 995 unselected (i.e. 'all-comers') patients in nine different centres in India. ${ }^{59}$ Strut coverage, as assessed with OCT at 6 months' follow-up, was excellent.

Subsequently, the prospective, randomized, multicentre TALENT trial (NCT02870140) was conducted throughout Europe..$^{60}$ A total of 1,435 patients were randomized 1:1 to either Supraflex or Xience. More than half (59\%) of the patients had acute coronary syndrome as initial diagnosis, of whom $16 \%$ had STEMI. Around one-quarter (23\%) had diabetes, $66 \%$ had a history of hypertension, $61 \%$ had hypercholesterolaemia, $8 \%$ had established peripheral vascular disease and only $2 \%$ had renal insufficiency. Left main stenting was infrequent (1.5\%), and the average number of lesions per patient was $1.4 ; 16 \%$ had $\mathrm{PCl}$ for a bifurcation lesion and $4 \%$ had $\mathrm{PCl}$ for restenotic lesions. The primary endpoint was non-inferiority of the Supraflex stent to the Xience stent with regard to a device-oriented composite endpoint of cardiac death, target-vessel $\mathrm{MI}$ or clinically indicated TLR at 12-month follow-up. The primary 
Figure 3: Pooled estimates comparing ultrathin drug-eluting stents with second-generation drug-eluting stents for key clinical endpoints

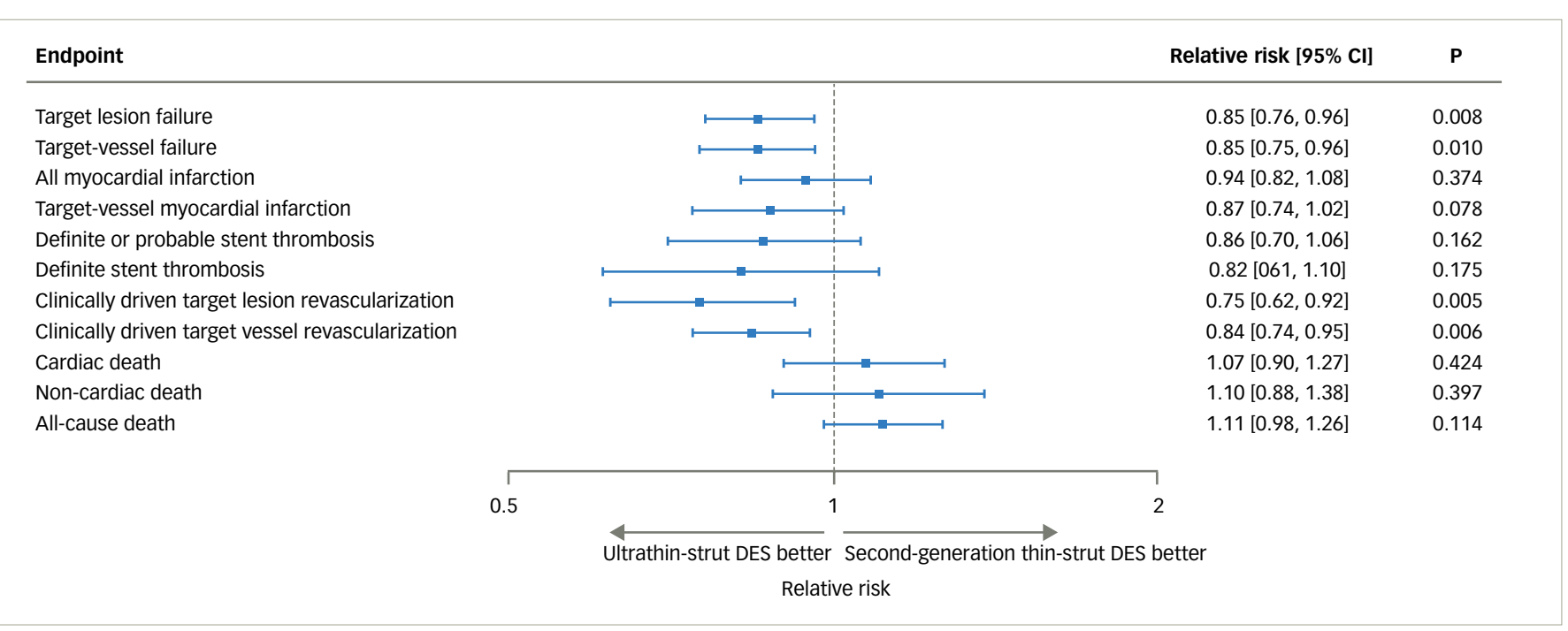

Results from a random-effects meta-analysis of 16 trials including 20,701 patients randomized to the ultrathin-strut ( $\leq 70 \mu \mathrm{m}$ strut thickness) DES and conventional secondgeneration DES. Weighted mean of follow-up duration was 2.5 years. Reproduced with permission from Madhaven et al., 2021.62

$\mathrm{Cl}=$ confidence interval; $\mathrm{DES}=$ drug-eluting stents.

device-oriented outcome had occurred in $4.9 \%$ of the supraflex group and $5.3 \%$ of the Xience group ( $p$ for non-inferiority $<0.0001$ ) at 12 months. There were no between-group differences in individual clinical endpoints except for any death, which was higher in the Supraflex group than the Xience group (2.0\% versus $0.6 \%$, respectively; $\mathrm{p}=0.019)$. However, cardiac death rates were similar $(1.0 \%$ versus $0.3 \%$, respectively; $\mathrm{p}=0.097)$. Definite/probable ST rates were very low in both groups $(0.8 \%$ versus $0.9 \%$, respectively; $p=0.996) . .^{60}$ At 2 -year follow-up, the device-oriented composite endpoint had occurred in $6.9 \%$ of the Supraflex group and $7.9 \%$ of the xience group ( $p=0.491)$. Rates of any death $(2.5 \%$ versus $3.0 \%$, respectively; $p=0.640)$ and cardiac death $(1.3 \%$ versus $1.6 \%$, respectively; $p=0.659$ ) were not different between groups. Rates of target-vessel $\mathrm{Ml}(3.0 \%$ versus $3.8 \%$, respectively; $\mathrm{p}=0.382)$ and clinically indicated TLR (4.7\% versus $5.3 \%$, respectively; $p=0.627$ ) were also similar between groups. Definite/probable stent thrombosis rates remained very low and similar in the Supraflex and Xience groups (1.1\% versus $1.3 \%$, respectively; $p=0.813$ ). ${ }^{.1}$

Although clinical outcomes are limited, the first results of the Supraflex stent are promising. Importantly, the Supraflex Cruz, Everoflex, Tetriflex and Tetrilimus stents have not yet been randomly compared with other DES.

\section{BioMime $^{\mathrm{TM}}$}

In the meriT-V randomized trial (NCT02112981), 256 patients from 15 centres throughout Europe were randomized in a 2:1 fashion to either the BioMime stent or the Xience stent. ${ }^{62}$ Patients initially diagnosed with $\mathrm{MI}$ were excluded. Lesion length up to $44 \mathrm{~mm}$ was allowed, with a maximum of two lesions. Complex lesions (e.g. severely calcified lesions, bifurcations, restenotic or left main lesions) were excluded. The primary endpoint was non-inferiority of the BioMime stent to the Xience stent with regard to in-stent late lumen loss at 9 months. The study met its primary endpoint: in-stent late lumen loss was $0.15 \pm$ $0.27 \mathrm{~mm}$ (mean $\pm \mathrm{SD}$ ) in the BioMime group and $0.15 \pm 0.29 \mathrm{~mm}$ in the Xience group (difference, $-0.006 \mathrm{~mm}$; $95 \% \mathrm{Cl},-0.085-0.072$; $\mathrm{p}$ for non-inferiority $<0.0001)$. MACE rate, defined as the composite of cardiac death, $\mathrm{MI}$ and ischaemia-driven TVR was numerically lower in the BioMime group than the Xience group (2.98\% versus $7.14 \%$, respectively; $p=0.13)$, driven by a statistically significant between-group difference in the occurrence of $\mathrm{MI}(0.6 \%$ in the BioMime group versus $4.8 \%$ in the Xience group; $p=0.03)$. However, there was no difference in target vessel-related $\mathrm{MI}$ rates $(0.6 \%$ in the BioMime group versus $1.2 \%$ in the Xience group; $\mathrm{p}=0.62$ ) and definite/probable stent thrombosis rates ( $0 \%$ in both groups) between groups. ${ }^{62}$

Although these angiographic results are promising and may lead to excellent and comparable revascularization rates compared with other DES, clinical trials powered for clinical endpoints are needed to confirm this.

\section{Meta-analysis}

The above-described randomized trials have been included in a recent meta-analysis. ${ }^{63}$ In total, 16 randomized trials comparing ultrathin-strut DES with second-generation DES were included in the analysis. A total of 20,701 patients were included, and the mean follow-up duration was 2.5 years. TLF was defined as the composite of cardiac death, MI or clinically driven TLR. DES with ultrathin struts, compared with second-generation DES, were associated with a significant $15 \%$ reduction in TLF (relative risk, 0.85; 95\% Cl, 0.76-0.96; $\mathrm{p}=0.008$ ) (Figure 3). ${ }^{62}$ This was mainly due to a significant $25 \%$ reduction in clinically driven TLR rate (relative risk, $0.75 ; 95 \% \mathrm{Cl}, 0.62-0.92 ; \mathrm{p}=0.005$ ) (Figure 3). Clinically driven TVR rate was also lower with the ultrathin-strut DES (relative risk, 0.84; 95\% Cl, 0.74-0.95; $\mathrm{p}=0.006$ ). There were no significant differences with regard to other components individually (MI, stent thrombosis, and cardiac death) (Figure 3). ${ }^{63}$

\section{Conclusions}

DES with ultrathin struts $(<70 \mu \mathrm{m})$ have shown promising clinical results in further improving clinical outcomes after PCl. Individual randomized trials (mainly involving the Orsiro DES) have consistently shown that ultrathin-strut DES with biodegradable polymers are non-inferior to second-generation DES, mainly the xience DES, eluting everolimus from a durable polymer with strut thickness of $81 \mu \mathrm{m}$. In a recent meta-analysis, there was a statistically significant long-term (2.5 years) clinical improvement with the ultrathin-strut DES compared with the second-generation DES in terms of TLF and TVF, driven by differences in 
TLR and TVR rates. ${ }^{63}$ However, the relative risk reduction of $15 \%$ in both TVF and TLF was modest, and absolute risk reduction was low given the already very favourable results with second-generation DES ( 8.3\% of TLF in the control group at 2.5 years). This means that, in absolute terms, reduction in TLF was modest ( 1.2\%). Furthermore, in terms of safety, $\mathrm{Ml}$ and cardiac death rates were not statistically significantly reduced. In patients with STEMI, the Orsiro stent may be superior to other non-ultrathin second-generation DES. ${ }^{37-40}$ On the other hand, in some lesions, such as heavily calcified lesions or CTOs (as shown in PRISON IV), the ultrathin-strut stents may perform less favourably than their second-generation counterparts using the same alloy but thicker struts, although more studies are needed to clarify this. ${ }^{31}$

In conclusion, the newest generation ultrathin-strut DES with biodegradable polymers are 'here to stay' as an attractive alternative to other second- and third-generation DES. $\square$
1. Sigwart U, Puel J, Mirkovitch V, et al. Intravascular stents to prevent occlusion and restenosis after transluminal angioplasty. N Engl J Med. 1987;316:701-6.

2. Fischman $D L$, Leon $M B$, Baim DS, et al. A randomized comparison of coronary-stent placement and balloon angioplasty in the treatment of coronary artery disease. Stent Restenosis Study Investigators. N Engl I Med. 1994;331:496-501.

3. Serruys PW, de Jaegere P, Kiemeneij F, et al. A comparison of balloon-expandable-stent implantation with balloon angioplasty in patients with coronary artery disease. Benestent Study Group. N Eng/ J Med. 1994;331:489-95.

4. Babapulle MN, Joseph L, Bélisle P, et al. A hierarchical Bayesian meta-analysis of randomised clinical trials of drug-eluting stents. Lancet. 2004:364:583-91.

5. Bønaa KH, Mannsverk J, Wiseth R, et al. Drug-eluting or bare-metal stents for coronary artery disease. N Engl I Med. 2016:375:1242-52.

6. Daemen J, Wenaweser P, Tsuchida K, et al. Early and late coronary stent thrombosis of sirolimus-eluting and paclitaxel-eluting stents in routine clinical practice: data from a large two-institutional cohort study. Lancet. 2007;369:667-8.

7. Joner M, Finn AV, Farb A, et al. Pathology of drug-eluting stents in humans: delayed healing and late thrombotic risk. J Am Coll Cardiol. 2006;48:193-202.

8. Kipshidze N, Dangas $\mathrm{G}$, Tsapenko $\mathrm{M}$, et al. Role of the endothelium in modulating neointimal formation: vasculoprotective approaches to attenuate restenosis after percutaneous coronary interventions. J Am Coll Cardiol. 2004;44:733-9.

9. Soucy NV, Feygin JM, Tunstall R, et al. Strut tissue coverage and endothelial cell coverage: a comparison between bare metal stent platforms and platinum chromium stents with and without everolimus-eluting coating. Eurolntervention. and without ever $2010 ; 630-7$.

10. Kolandaivelu K, Swaminathan R, Gibson WJ, et al. Stent thrombogenicity early in high-risk interventional settings is driven by stent design and deployment and protected by polymer-drug coatings. Circulation. 2011;123:1400-9.

11. Timmins LH, Miller MW, Clubb FJ, Moore JE. Increased artery wall stress post-stenting leads to greater intimal thickening. Lab Invest. 2011;91:955-67.

12. Tenekecioglu E, Torii R, Bourantas CV, et al. Non-Newtonian pulsatile shear stress assessment: a method to differentiate bioresorbable scaffold platforms. Eur Heart J. 2017;38:2570,

13. Bourantas CV Räber L, Zaugg S, et al. Impact of local endothelial shear stress on neointima and plaque following stent implantation in patients with ST-elevation myocardial infarction: A subgroup-analysis of the COMFORTABLE AMIIIBIS 4 trial Int I Cardiol 2015:186:178-85.

14. Sotomi $Y$, Onuma $Y$, Collet $C$, et al. Bioresorbable scaffold: the emerging reality and future directions. Circ Res. 2017;120:1341-52.

15. Kastrati A, Mehilli J, Dirschinger J, et al. Intracoronary stenting and angiographic results: strut thickness effect on restenosis outcome (ISAR-STEREO) trial. Circulation. 2001;103:2816-21.

16. Topol EJ, Nissen SE. Our preoccupation with coronary luminology. The dissociation between clinical and angiographic findings in ischemic heart disease. Circulation. 1995;92:2333-42

17. Rittersma SZH, de Winter RJ, Koch KT, et al. Impact of strut thickness on late luminal loss after coronary artery stent placement. Am J Cardiol. 2004;93:477-80.

18. Chichareon $P$, Katagiri $Y$, Asano $T$, et al. Mechanical properties and performances of contemporary drug-eluting stent: focus on the metallic backbone. Expert Rev Med Devices 2019:16:211-28

19. Lupi A, Gabrio Secco G, Rognoni A, et al. Meta-analysis of bioabsorbable versus durable polymer drug-eluting stents in 20,005 patients with coronary artery disease: an update Catheter Cardiovasc Interv. 2014;83:E193-206.

20. Schmidt W, Lanzer P, Behrens $P$, et a;. A comparison of the mechanical performance characteristics of seven drug-eluting stent systems. Catheter Cardiovasc Interv. 2009;73:350-60.

21. Bonin M, Guerin P, Olive JM, et al. Standardized bench test evaluation of coronary stents: Biomechanical characteristics. Catheter Cardiovasc Interv. 2018:92:E465-70.

22. Hong MK, Park SW, Lee CW, et al. Intravascular ultrasound comparison of chronic recoil among different stent designs. Am J Cardiol. 1999:84:1247-50

23. Watson T, Webster MWI, Ormiston JA, et al. Long and short of optimal stent design. Open Heart. 2017;4:e000680.

24. Menown IBA, Noad R, Garcia EJ, Meredith I. The platinum chromium element stent platform: from alloy, to design, to clinical practice. Adv Ther. 2010;27:129-41.
25. Schmidt T, Abbott JD. Coronary stents: history, design, and construction. J Clin Med. 2018;7:126.

26. Gurbel PA, Callahan KP, Malinin Al, et al. Could stent design affect platelet activation? Results of the Platelet Activation STenting (PAST) Study. J Invasive Cardiol. 2002;14:584-9.

27. Sangiorgi G, Melzi G, Agostoni P, et al. Engineering aspects of stents design and their translation into clinical practice. Ann Ist Super Sanita. 2007;43:89-100.

28. Ormiston JA, Webster MWI, El Jack S, et al. Drug-eluting stents for coronary bifurcations: bench testing of provisional side-branch strategies. Catheter Cardiovasc Interv. 2006;67:49-55.

29. Windecker S, Haude M, Neumann F-J, et al. Comparison of a novel biodegradable polymer sirolimus-eluting stent with a durable polymer everolimus-eluting stent: results
of the randomized BIOFLOW-II trial. Circ Cardiovasc Interv. 2015;8:e001441.

30. Improta R, Scarparo P, Wilschut J, et al. Elastic stent recoil in coronary total occlusions: Comparison of durable-polymer zotarolimus eluting stent and ultrathin strut bioabsorbable-polymer sirolimus eluting stent. Catheter Cardiovasc Interv. 2021 doi: 10.1002/ccd.29739. Online ahead of print.

31. Teeuwen K, van der Schaaf RJ, Adriaenssens T, et al. Randomized multicenter trial investigating angiographic outcomes of hybrid sirolimus-eluting stents with biodegradable polymer compared with everolimus-eluting stents with durable polymer in chronic total occlusions: The PRISON IV trial. JACC Cardiovasc Interv. 2017;10:133-43.

32. Saito S, Toelg R, Witzenbichler B, et al. BIOFLOW-IV, a randomised, intercontinental, multicentre study to assess the safety and effectiveness of the Orsiro sirolimus-eluting stent in the treatment of subjects with de novo coronary artery lesions: primary outcome target vessel failure at 12 months. Eurolntervention. 2019;15:e1006-13.

33. Kandzari DE, Mauri L, Koolen JJ, et al. Ultrathin, bioresorbable polymer sirolimus-eluting stents versus thin, durable polymer everolimus-eluting stents in patients undergoing coronary revascularisation (BIOFLOW V): a randomised trial. Lancet. 2017;390:1843-52

34. Kandzari DE, Koolen JJ, Doros G, et al. Ultrathin bioresorbable-polymer sirolimus-eluting stents versus thin durable-polymer everolimus-eluting stents for coronary revascularization: 3-year outcomes from the randomized BIOFLOW V trial. JACC Cardiovasc Interv. 2020;13:1343-53,

35. Li C, Yang Y, Han Y, et al. Comparison of the ultrathin strut, biodegradable polymer sirolimus-eluting stent with a durable polymer everolimus-eluting stent in a chinese population: the randomized BIOFLOW VI trial. Clin Ther. 2020;42:649-60.e9.

36. Pilgrim T, Heg D, Roffi M, et al. Ultrathin strut biodegradable polymer sirolimus-eluting stent versus durable polymer everolimus-eluting stent for percutaneous coronary revascularisation (BIOSCIENCE): a randomised, single-blind, non-inferiority trial. Lancet. 2014;384:2111-22.

37. Pilgrim T, Piccolo R, Heg D, et al. Ultrathin-strut, biodegradable-polymer, sirolimus-eluting stents versus thin-strut, durable-polymer, everolimus-eluting stents for percutaneous coronary revascularisation: 5-year outcomes of the BIOSCIENCE randomised trial. Lancet. 2018;392:737-46.

38. Pilgrim T, Muller $\mathrm{O}$, Heg D, et al. Biodegradable- versus durable-polymer drug-eluting stents for STEMI: Final 2-year outcomes of the BIOSTEMI trial. JACC CardiovasC Interv. 2021:14:639-48.

39. Iglesias JF, Muller O, Heg D, et al. Biodegradable polymer sirolimus-eluting stents versus durable polymer everolimus-eluting stents in patients with ST-segment elevation myocardial infarction (BIOSTEMI): a single-blind, prospective, randomised superiority trial. Lancet. 2019;394:1243-53.

40. Jensen LO, Thayssen P, Maeng M, et al. Randomized comparison of a biodegradable polymer ultrathin stru sirolimus-eluting stent with a biodegradable polymer biolimus-eluting stent in patients treated with percutaneous coronary intervention: The SORT OUT VII trial. Circ Cardiovasc Interv. 2016;9:e003610

41. Ellert J, Maeng M, Raungaard B, et al. Clinical outcomes three-year after revascularization with biodegradable polymer stents: ultrathin-strut sirolimus-eluting stent versus bolymer stents: ultrathin-strut sirolimus-eluting stent versus biolimus-eluting stent: from the Scandinavian organization for
randomized trials with clinical outcome VII trial. Coron Artery randomized trials with
Dis. 2020;31:485-92.

42. Jensen LO, Maeng M, Raungaard B, et al. Randomized comparison of the polymer-free biolimus-coated BioFreedom stent with the ultrathin strut biodegradable polyme sirolimus-eluting orsiro stent in an all-comers population treated with percutaneous coronary intervention: The SORT
OUT IX trial Circulation. 2020:141:2052-63.

43. Jakobsen $L$, Christiansen EH, Freeman P, et al. Randomized clinical comparison of the dual-therapy CD34 antibody-covered sirolimus-eluting combo stent with the sirolimus-eluting Orsiro stent in patients treated with percutaneous coronary intervention: The SORT OUT X trial. Circulation. 2021;143:2155-65.

44. von Birgelen C, Kok MM, van der Heijden LC, et al. Very thin strut biodegradable polymer everolimus-eluting and sirolimus-eluting stents versus durable polymer zotarolimus-eluting stents in allcomers with coronary artery disease (BIO-RESORT): a three-arm, randomised, non-inferiority trial. Lancet. 2016;388:2607-17.

45. Buiten RA, Ploumen EH, Zocca P, et al. Thin, very thin, or ultrathin strut biodegradable or durable polymer-coated drug-eluting stents: 3 -year outcomes of BIO-RESORT. JACC drug-eluting stents: 3-year outcomes

46. Kang S-H, Chung W-Y, Lee JM, et al. Angiographic outcomes of Orsiro biodegradable polymer sirolimus-eluting stents and Resolute Integrity durable polymer zotarolimus-eluting stents:
results of the ORIENT trial. Eurolntervention. 2017;12:1623-31.

47. Kim S-H, Kang S-H, Lee JM, et al. Three-year clinical outcome of biodegradable hybrid polymer Orsiro sirolimus-eluting stent and the durable biocompatible polymer Resolute Integrity zotarolimus-eluting stent: A randomized controlled trial. Catheter Cardiovasc Interv. 2020;96:1399-1406.

48. von Birgelen C, Zocca P, Buiten RA, et al. Thin composite wire strut, durable polymer-coated (Resolute Onyx) versus ultrathin cobalt-chromium strut, bioresorbable polymer-coated (Orsiro) drug-eluting stents in allcomers with coronary artery disease (BIONYX): an international, single-blind, randomised (BIONYX): an international, single-blind, random
non-inferiority trial. Lancet. 2018:392:1235-45.

49. Medtronic. Resolute Onyx DES for coronary artery disease Available at: www.medtronic.com/us-en/healthcareprofessionals/products/cardiovascular/stents/resolute-onyxdes.html (accessed 15 November 2021)

50. Ploumen EH, Buiten RA, Zocca P, et al. First report of 3-yea clinical outcome after treatment with novel Resolute Onyx stents in the randomized BIONYX trial. Circ J. 2021;85:1983-90.

51. Yoon C-H, Choi YJ, Park JJ, et al. BioMatrix versus Orsiro biodegradable polymer stents in all-comer patients with coronary artery disease: the multicentre, randomised BIODEGRADE trial. Eurolntervention. 2021;16:1404-12.

52. Zivelonghi C, Agostoni P, Teeuwen K, et al. 3-year clinical outcomes of the PRISON-IV trial: ultrathin struts versus conventional drug-eluting stents in total coronary occlusions. JACC Cardiovasc Interv 2019:12:1747-9.

53. Ormiston 」, Webster M Stewart 」, et al. First-in-human evaluation of a bioabsorbable polymer-coated sirolimus-eluting stent: imaging and clinical results of the DESSOLVE I Trial (DES with sirolimus and a bioabsorbable polymer for the treatment
of patients with de novo lesion in the native coronary arteries). JACC Cardiovasc Interv. 2013;6:1026-34.

54. Wijns W, Vrolix M, Verheye $S$, et al. Randomised study of a bioabsorbable polymer-coated sirolimus-eluting stent: results of the DESSOLVE II trial. Eurolntervention. 2015;10:1383-90.

55. Wijns W, Vrolix M, Verheye S, et al. Long-term clinical outcomes of a crystalline sirolimus-eluting coronary stent with a fully bioabsorbable polymer coating: five-year outcomes from the DESSOLVE I and II trials. Eurolntervention. 2018;13:e2147-51.

56. de Winter RJ, Katagiri Y, Asano T, et al. A sirolimus-eluting bioabsorbable polymer-coated stent (Mistent) versus an everolimus-eluting durable polymer stent (Xience) after percutaneous coronary intervention (DESSOLVE III): a randomised, single-blind, multicentre, non-inferiority, phase 3 randomised, single-blind, multice
trial. Lancet. 2018;391:431-40.

57. Katagiri $Y$, Onuma $Y$, Lurz $P$, et al. Clinical outcomes of bioabsorbable polymer sirolimus-eluting stents versus durable polymer everolimus-eluting stents: two-year follow-up of the DESSOLVE III trial. Eurolntervention. 2020;15:e1366-74.

58. Takahashi K, Serruys PW, Kogame N, et al. Final 3-year outcomes of Mistent biodegradable polymer crystalline sirolimus-eluting stent versus Xience permanent polymer everolimus-eluting stent: insights from the DESSOLVE. III All-Comers Randomized Trial. Circ Cardiovasc Interv. 2020;13:e008737.

59. Lemos PA, Chandwani P, Saxena S, et al. Clinical outcomes in 995 unselected real-world patients treated with an ultrathin biodegradable polymer-coated sirolimus-eluting stent: 12-month results from the FLEX Registry. BMJ Open. 2016;6:e010028

60. Zaman A, de Winter RJ, Kogame N, et al. Safety and efficacy of a sirolimus-eluting coronary stent with ultra-thin strut for treatment of atherosclerotic lesions (TALENT): a prospective multicentre randomised controlled trial. Lancet. 2019;393:987-97. 
61. Gao C, Kogame N, Sharif F, et al. Prospective multicenter randomized all-comers trial to assess the safety and effectiveness of the ultra-thin strut sirolimus-eluting coronary stent Supraflex: two-year outcomes of the TALENT trial. stent Supraflex: two-year outcomes of the
62. Abizaid A, Kedev S, Kedhi E, et al. Randomised comparison of a biodegradable polymer ultra-thin sirolimus-eluting stent versus a durable polymer everolimus-eluting stent in patients with de novo native coronary artery lesions: the meriT-V trial. Eurolntervention. 2018:14:e1207-14.
63. Madhavan MV, Howard JP, Naqvi A, et al. Long-term follow-up after ultrathin vs. conventional 2nd-generation drug-eluting stents: a system. conc review and meta- analysis of randuting controlled trials. Eur Heart J. 2021:42:2643-54. 